\title{
Personal experience with the procurement of 132 liver allografts
}

\author{
K. Yanaga ${ }^{1}$, A.G. Tzakis $^{2}$, and T.E. Starzl ${ }^{1}$ \\ ${ }^{1}$ Department of Surgery, University Health Science Center of Pittsburgh, University of Pittsburgh, \\ Falk Clinic 4 West, 3601 Fifth Avenue, Pittsburgh, PA 15213, USA \\ ${ }^{2}$ The Veterans Administration Medical Center, University Drive C, Pittsburgh, PA 15213, USA
}

\begin{abstract}
A single donor surgeon's experience procuring the livers from 132 donors is described. Thirty-seven grafts $(28.9 \%)$ had hepatic arterial anomalies, $19(14.4 \%)$ of which required arterial reconstruction prior to transplantation. Of the 121 grafts evaluated for early function, 103 grafts $(85.2 \%)$ functioned well, whereas 14 grafts $(11.6 \%)$ functioned poorly and 4 grafts (3.3\%) failed to function at all. The variables associated with less than optimal function of the graft consisted of donor age $(P<0.05)$, duration of donor's stay in the intensive care unit $(P<0.005)$, abnormal graft appearance $(P<0.05)$, and such recipient problems as vascular thromboses during or immediately following transplantation $(P<0.005)$. A new preservation fluid, University of Wisconsin solution, allowed safe and longer cold storage of the liver allograft than did Euro-Collins' solution $(P<0.0001)$. A parameter of liver allograft viability, which is simple and predictive of allograft function prior to the actual transplant procedure, is urgently needed.
\end{abstract}

\section{Keywords}

Liver transplantation; procurement - Procurement; of the liver - Arterial anomalies and liver procurement

Enormous progress has been achieved during the last 25 years since the first orthotopic liver transplantation (OLTx) was performed in humans in 1963. With improvements in the overall outcome of the recipients, OLTx has established its role as a therapeutic option for patients with end-stage liver disease [3,20,22]. For this major surgical procedure to succeed, however, it is essential that the liver allograft functions immediately. Primary graft nonfunction remains a dreadful complication of OLTx, one that is associated with a high mortality and morbidity [18]. Our previous study on donor selection and the clinical outcome of OLTx, however, demonstrated a poor correlation between all presently available donor parameters and the early outcome of OLTx [13]. The approach that most transplant centers currently take to procuring liver allografts seems to involve the delegation of surgeons who are experienced in the field of organ procurement and to whom the final assessment of the quality of the graft is assigned. In this report, the personal experience of 132 allograft hepatectomies by a single surgeon is analyzed in order to identify the role of a number of variables pertinent to the clinical outcome of OLTx.

\section{Materials and methods}

During the 21-month period between 29 January 1987 and 1 September 1988, 132 allograft hepatectomies were performed by a single donor surgeon (K.Y.). Of these, 128 livers (97\%) 
were transplanted orthotopically to a total of Inpatients with end-stage liver disease at the University of Pittsburgh Health Center. The other 4 livers were not transplanted and were, therefore, excluded from the study. In three cases this was due to the poor quality of the graft, which had multiple liver lacerations (as a result of a motor vehicle accident), possible portal vein thrombosis, and fatty liver associated with size discrepancy from the recipient liver. In another case there was a major size discrepancy, the allograft liver from a 2-day-old neonate being too small for the only remaining recipient. All donors were brain dead and all but five were heart-beating cadavers. In these five grafts, unexpected cardiac arrest occurred immediately before or during procurement of the liver, and cardiopulmonary resuscitation was performed. The age of the donors varied from 3 months to 48 years, with a mean of 23.8 years. Seventy-nine $(61.7 \%)$ of the donors were male. Table 1 lists the causes of death of the donors. All donors were located in North America, 124 in the United States and 4 in Canada (Fig. 1).

\section{Donor selection criteria}

Patients who might potentially have transmitted any disease were excluded from consideration as organ donors. Because of the absence of a correlation between the traditional parameters of donor assessment and the early outcome of OLTx in the previous study [13], no rigid criteria were established for donor selection. Instead, selection was primarily made on an individual basis, depending upon the condition of the potential recipient. In general, donors were selected who were less than 50 years of age, who had no history of liver disease such as hepatitis or alcoholism, and who had a total serum bilirubin less than $2.0 \mathrm{mg} / \mathrm{dl}$, normal or near-normal SGOT, SGPT, and prothrombin time, and an adequate arterial blood gas. Elevations of SGOT or SGPT, with a tendency to decline, were not regarded as a contraindication for donation of the liver.

\section{Donor maintenance}

Donors were fluid-resuscitated once they had been pronounced brain dead in order to maintain a central venous pressure of $8-10 \mathrm{~cm} \mathrm{H}_{2} \mathrm{O}$ and urine output over $1 \mathrm{ml} / \mathrm{kg}$ per hour as a guide. For donors receiving vasopressin for diabetes insipidus, the vasopressin was discontinued as soon as possible to avoid liver ischemia secondary to a decreased splanchnic blood flow. Urine output was replaced vigorously with intravenous fluids, usually one-half or quarter normal saline solution with potassium chloride. Electrolytes were checked frequently, especially to correct hypokalemia. Normothermia was maintained with a thermoblanket. Ninety-two donors (71.9\%) required vasopressor support. Dopamine was the primary choice since it is known to preserve splanchnic blood flow $[6,16]$. The use of pure alpha stimulators, such as norepinephrine bitartrate (Levophed), was avoided. Blood was transfused to maintain the hematocrit above $30 \%$ in order to maintain adequate oxygen delivery to the tissues.

\section{Operative technique}

The technique of allograft hepatectomy involved both rapid perfusion and modified rapid perfusion.

Rapid perfusion technique $(n=60)$-This technique has been described in detail elsewhere [23]. Briefly, both the terminal aorta and the inferior mesenteric vein were dissected to insert aortic and portal perfusion cannulae. The supraceliac abdominal aorta was encircled and crossclamped. Following cardiectomy, dissection of the liver hilum was performed in a bloodless field. Following identification in the retropancreatic portion, the right side of the superior mesenteric artery (SMA) was dissected toward the aorta, searching for an aberrant right hepatic artery (HA) originating from the SMA. A Carrel patch of aorta was excised, with care not to injure the origin of the renal arteries. This has been our preferred method of 
hepatectomy in children or unstable donors, or in cases of extreme urgency when the recipient is in fulminant liver failure due to fulminant hepatitis or graft nonfunction following OLTx.

Modified rapid perfusion technique $(n=68)$-This differs from the rapid perfusion technique in that dissection of the liver hilum occurs prior to crossclamping of the aorta and cannulation of the distal splenic vein with a larger caliber catheter for a quicker portal perfusion. This preliminary dissection allows more selective and rapid cooling of the liver than does the rapid perfusion technique. These additional preparatory steps required $30-45 \mathrm{~min}$. This technique has been our choice for stable adult donors and for donors whose livers are of a questionable quality. During the preparatory dissection, changes in the color or consistency of the allograft were observed in response to diuresis, better oxygenation, or bowel rest following extensive renal dissection by a kidney team.

\section{Method of organ preservation}

First, 49 livers were harvested using in situ perfusion with lactated Ringer's or Euro-Collins' solution $\left(4^{\circ} \mathrm{C}\right)$. This was followed by ex vivo flush with Euro-Collins' solution $\left(4^{\circ} \mathrm{C}\right)$.

Thereafter, the livers were preserved by ex vivo perfusion at the back table with University of Wisconsin (UW) solution $\left(4^{\circ} \mathrm{C}\right)[1]$.

\section{Technique of vascular reconstruction for arterial anomalies}

Arterial reconstruction of the liver graft is required prior to transplantation if a common arterial channel is absent due to an anomaly. The most common arterial anomaly requiring reconstruction was the aberrant right HA arising from the SMA, for which an end-to-end anastomosis was performed between the distal donor splenic artery and the proximal aberrant right HA. This was achieved with a Carrel patch of the SMA, obviating a small caliber anastomosis [9]. Care was taken to avoid an inadvertent anastomosis with rotation. The continuous suture technique with 7-0 monofilament polypropolene (Prolene), as described by Starzl et al. [21], was used for the reconstruction. Just before the sutures were tied, the reconstructed HA was allowed to distend by pulsatile infusion of cold solution while the distal HA was occluded digitally. With the application of "growth factor" principle [21] to the ex vivo condition, this method facilitated migration of Prolene sutures into the anastomosis and allowed secure anastomosis without leakage or stricture.

\section{Classification of the early graft function}

Early graft function in the recipients who survived the transplant procedure (121 grafts, 112 patients) was classified as good, fair, poor, or graft nonfunction, according to the poorest category into which any of the parameters fell (Table 2). Graft nonfunction was defined as the inability of the graft to sustain the metabolic homeostasis of a recipient during the 1st postoperative week, presenting with the clinical manifestations of grade III or IV coma, coagulopathy with prothrombin time over $20 \mathrm{~s}$, high SGOT and SGPT values, renal failure, and progressive or persistent hyperbilirubinemia, resulting in retransplantation of the graft or death of the recipient.

\section{Analysis of the correlation between the donor or allograft variables and early graft function}

In order to analyze the significance of the donor or allograft factors on the quality of grafts harvested by a single donor surgeon, the donor or allograft variables were analyzed in relation to the early graft function of 109 grafts in 102 patients who survived the operative procedure and who did not develop intraoperative or immediately postoperative complications that adversely affected the quality of the grafts. The exclusion of 19 patients (15.7\%) was due to intraoperative mortality from hemorrhage during hepatectomy due to technical difficulties $(n$ $=6$ ), intraoperative cardiac failure due to cardiomyopathy $(n=1)$, HA thrombosis $(n=6)$, severe 
HA stenosis $(n=1)$, portal vein thrombosis $(n=2)$, severe pancreatitis $(n=2)$, and prolonged warm ischemia during the revision of the suprahepatic caval anastomosis after initial revascularization $(n=1)$. None of the grafts excluded from the analysis of early graft function was attributed or thought to have contributed to the development of the problems described above.

High dose vasopressors were defined as dopamine of over $10 \mu \mathrm{g} / \mathrm{kg}$ per minute or additional alpha stimulators. The appearance of the graft was classified as abnormal when the liver either felt firm or exhibited discoloration.

\section{Statistical analyses}

Student's $t$ - and chi-square tests were used for the statistical evaluation of the data.

\section{Results}

\section{Vascular anomalies}

Table 3 lists the incidence of hepatic arterial anomalies and various methods of arterial reconstruction. Hepatic arterial anomalies were present in 37 grafts (28.9\%): the aberrant right HA in $14(10.9 \%)$, the aberrant left HA in 17 (13.3\%), and both aberrant right and left hepatic arteries in 6 grafts $(5 \%)$. Of these, 19 grafts $(51.4 \%)$ required vascular reconstruction at the back table in order to construct a common arterial channel. One (5.3\%) of the anastomoses constructed at the back table required the revision due to rotation, but none became the cause of postoperative HA thrombosis.

\section{Complications}

A total of four complications (3.1\%) occurred during or after allograft hepatectomy: aortic rupture while encircling the supraceliac abdominal aorta prior to crossclamping, inadvertent transection of the aberrant right HA, once originating directly from the aorta and once from the left side of the SMA, and avulsion injury of the origin of the splenic artery of a pediatric liver during dissection of the HA at the back table. The aortic rupture necessitated rapid removal of organs from the donor. All of the grafts harvested from that donor (heart, liver, and kidneys) functioned well in the recipients. The transected aberrant right hepatic arteries were reconstructed using end-to-end anastomosis with the donor splenic artery, as in other cases, without any difficulty. The avulsion injury of the origin of the splenic artery was repaired with interrupted 8-0 Prolene sutures, and the HA remained patent postoperatively. Overall, none of the complications affected the outcome of the liver or other organ recipients.

\section{Early graft function}

Table 4 lists the early graft function of the 121 allografts after OLTx. Graft function was good or fair in 97 out of $109(89 \%)$ of the grafts without recipient problems, whereas as many as 6 out of $12(50 \%)$ of the grafts with recipient problems during or immediately following OLTx exhibited poor or nonfunction $\left(P<0.005 ; \chi^{2}=12.81\right)$. Table 5 shows the correlation between the donor or graft variables and the early graft function of the 109 grafts in 102 patients who survived the operation and who did not develop the aforementioned recipient complications during or immediately following OLTx. A statistically significant difference was demonstrated in donor age, duration of patient's stay in the intensive care unit, and the presence of abnormal graft appearance. The donors of grafts with poor or nonfunction were significantly younger than those with good or fair function $(P<0.05)$. Furthermore, the donors of grafts with fair or poor function stayed in the intensive care unit longer than those with good function $(P<0.005)$, and the grafts with abnormal appearance were associated with a higher incidence of fair or poor graft function in recipients $\left(P<0.05 ; \chi^{2}=4.29\right)$. On the other hand, no definitive 
correlation with early graft function was observed in sex, results of liver function tests, cause of death, requirement of cardiopulmonary resuscitation or infusion of high-dose vasopressors, donor instability during procurement, or cold ischemia time.

\section{Effect of preservation solution on early graft function}

Of the 109 grafts analyzed in relation to early graft function, 39 were preserved in Euro-Collins' solution and 70 in UW solution (Table 6). Grafts preserved in UW solution had a significantly longer cold ischemia time than those stored in Euro-Collins' solution $(P<0.0001)$. However, as shown in Table 7, no statistical difference between the two groups was seen in the early liver function of the grafts.

\section{Recipient survival}

Of the 112 patients who received 121 liver allografts, 89 patients with 92 grafts (79.5\%) survived and were discharged; their follow-up period ranged from 1 to 21 months (mean 5.3 months). Of these, 87 patients with 90 grafts $(77.7 \%)$ remain alive and well.

\section{Discussion}

In this report, 132 liver allografts harvested by a single surgeon were analyzed. The donor or allograft variables pertinent to early graft function in this series were the age of the donor, duration of the donor's stay in the intensive care unit, and abnormal appearance of the graft.

The effect of increased donor age on the outcome of solid organ transplantation remains controversial. For cadaveric kidney transplantation, O'Connor et al. [15] reported in 1986 that kidney grafts from donors over 55 years of age achieved primary graft function and 1-year graft survival comparable to those from younger donors. Hong et al. [8] in 1981 and Foster et al. [5] in 1988, on the other hand, described a significantly lower incidence of immediate function and 1-year graft survival in cadaver allografts from donors over 50 years of age. Generally speaking, the upper age limit for the liver is arbitrarily set at 50 [28]. Aging creates morphological and functional alterations in the liver [4,27] and has been reported to be a discriminating factor in liver regeneration [17]. In liver surgery, on the other hand, chronological age does not seem to adversely affect the outcome of hepatic resection [29]. Our current approach towards the older donor consists of judicious selection, especially in older donors with a history of circulatory arrest of hemodynamic instability, based on the assumption that hepatic reserve is reduced with aging.

As to the hemodynamic stability of the donor, hypotension or the requirement of high-dose dopamine has been associated with nonfunction or delayed function, respectively, of kidney grafts [7,14]. Although no obvious harmful effects of cardiopulmonary resuscitation or of the requirement of high-dose vasopressors on the early function of the liver allograft were demonstrated in this study, these parameters strongly suggest suboptimal perfusion of the liver and warm ischemic injury. Since the success of OLTx is dependent on immediate function of the graft, we continue to apply cautious selection to donors with these variables.

As to the abnormal appearance of the graft, little is known about the correlation between gross appearance and quality of the graft. Livers from donors with diabetes insipidus, who have been on vasopressin for a prolonged period of time, are often firm and suggest the presence of ischemic injury. Since the use of vasopressin has been associated with a marked reduction in the blood flow to the liver [6], donors scheduled for liver procurement should be taken off vasopressin as soon as possible in order to minimize ischemic damage. Overhydration can distend the liver by an increase in central venous pressure and give a false impression as to the consistency of the liver. In our experience, the central venous pressure reading in the operating 
room is often unreliable. If the liver is distended from overhydration, the administration of intravenous diuretics or, if the donor has severe diabetes insipidus, simple discontinuation of intravenous fluids usually softens the liver.

The other significant factor related to early malfunction of the liver allograft was recipient problems during or immediately following OLTx, consisting mainly of vascular complications. The liver is a very vascular organ with a rich and complicated blood supply, and vascular complications during or after OLTx can easily ruin an optimal graft $[12,26]$.

Preservation of the integrity of the HA, while avoiding injury to renal arteries, is one of the important tasks of a donor surgeon. Intimal dissection of the donor artery has been reported as a cause of HA thrombosis, presumably due to inadvertent traction on the artery [2,11], and accidental transection of the aberrant arterial branches necessitates a vascular repair or manipulation of the small caliber arteries, which can lead to the development of dreaded HA thrombosis. The aberrant right HA arising from the SMA is by far the most common arterial anomaly requiring reconstruction prior to transplantation. Palpation of the posterior surface of the hepatoduodenal ligament before crossclamping of the aorta, however, is not always a reliable maneuver to identify the aberrant right HA. In this series, routine dissection of the right side of the SMA before transection of the hepatoduodenal ligament during allograft hepatectomy allowed for the preservation of the aberrant right HA originating from the SMA in all but one case.

Recently, a breakthrough in the preservation of the liver allograft was achieved by Belzer et al. [1,10]. Our experience with UW solution since October 1987 has confirmed the improved quality as well as safe prolongation of the preservation time of liver grafts preserved in UW solution, as compared to grafts stored in Euro-Collins' solution [24]. The prolongation of preservation time allows for more secure hemostasis during recipient hepatectomy, and histological evaluation of the graft prior to transplantation is now possible for grafts with steatosis [25].

For the assessment of organ viability in clinical OLTx, there is, to date, no practical and simple technique available that is discriminantly predictive of allograft function before the actual transplant procedure [9]. Since primary graft nonfunction remains a major cause of mortality, and since the shortage of donor organs remains a major limiting factor in clinical liver transplantation $[10,18]$, the development of such a predictive parameter is urgently needed in order to reduce mortality and morbidity related to early malfunction of the liver allograft.

\section{Acknowledgments}

This work was supported by research grants from the Veterans Administration and by project grant no. AM 29961 from the National Institutes of Health, Bethesda, Maryland. The authors thank Dr. Luis G.Podesta for his dedicated training of one of the authors (K.Y.) in organ procurement.

\section{References}

1. Belzer FO, Southard JH. Principles of solid-organ preservation by cold storage. Transplantation 1988;45:673-676. [PubMed: 3282347]

2. Blumhardt G, Ringe B, Lauchart W, Burdelski MB, Bechstein WO, Pichlmayr R. Vascular problems in liver transplantation. Transplant Proc 1987;19:2412. [PubMed: 3274527]

3. Busuttil RW, Colonna JO Jr, Hiatt JR, Brems JJ, Khoury GE, Goldstein LI, Ouinones-baldrich WJ, Abdul-Rasool IH, Ramming KP. The first 100 liver transplants at UCLA. Ann Surg 1987;206:387402. [PubMed: 3310930]

4. Dice JF. Cellular theories of aging as related to the liver. Hepatology 1985;5:508-513. [PubMed: 3997080] 
5. Foster MC, Wenham PW, Rowe PA, Blarney RW, Bishop MC, Burden RP, Morgan AG. Use of older patients as cadaveric kidney donors. Br J Surg 1988;75:767-769. [PubMed: 3048534]

6. Granger DN, Richardson PDI, Kvietys PR, Mortillaro NA. Intestinal blood flow. Gastroenterology 1980;78:837-863. [PubMed: 6101568]

7. Halloran P, Aprile M, Farewell V. Factors influencing early renal function in cadaver kidney transplants. Transplantation 1988;45:122-127. [PubMed: 3276040]

8. Hong JH, Shirani K, Arshad A, Parsa I, Matas A, Adamsons RJ, Butt KMH. Influence of cadaver donor age on the success of kidney transplantation. Transplantation 1981;32:532-534. [PubMed: 7041357]

9. Iu S, Harvey PRC, Makowka L, Petrunka CN, Ilson RG, Strasberg SM. Markers of allograft viability in the rat. Transplantation 1987;44:562-569. [PubMed: 3313844]

10. Kalayoglu M, Sollinger HW, Stratta RJ, D'Alessandro AM, Hoffmann RM, Pirsch JD, Belzer FO. Extended preservation of the liver for clinical transplantation. Lancet 1988;I:617-619. [PubMed: 2894550]

11. Klintmalm GB, Olson LM, Nery JR, Husberg BS, Paulsen AW. Treatment of hepatic artery thrombosis after liver transplantation with immediate vascular reconstruction: a report of three cases. Transplant Proc 1988;20:610-612.

12. Lerut J, Tzakis AG, Bron K, Gordon RD, Iwatsuki S, Esquivel CO, Makowka L, Todo S, Starzl TE. Complications of venous reconstruction in human orthotopic liver transplantation. Ann Surg 1987;205:404-414. [PubMed: 3551857]

13. Makowka L, Gordon RD, Todo S, Ohkohchi JW, Marsh JW, Tzakis AG, Yokoi H, Liqush J, Esquivel CO, Satake M, Iwatsuki S, Starzl TE. Analysis of donor criteria for the prediction of outcome in clinical liver transplantation. Transplant Proc 1987;19:2378-2382. [PubMed: 3103296]

14. Meurisse M, Albert A, Defraigne JO, Bonnet P, Honore P, Pierenne J, Henriuaux P, Mahiev P, Beaujean MA, Limet R, Jacquet N. Multiple risk factor analysis of non-immunological delayed graft function after kidney transplantation. Clin Transplant 1988;2:312-318.

15. O'Connor KJ, Franklin C, Bradley JW, Cho SI. The effect of increased donor age on kidney transplant outcome. Transplant Proc 1986;18:480-481.

16. Richardson PDI, Withrington PG. Liver blood flow: II. Effect of drugs and hormones on liver blood flow. Gastroenterology 1981;81:356-375. [PubMed: 6113188]

17. Shapiro H, Hotta SS, Outten WE, Klein AW. The effect of aging on rat liver regeneration. Experimentia 1982;38:1075-1076.

18. Shaw BW Jr, Gordon RD, Iwatsuki S, Starzl TE. Hepatic retransplantation. Transplant Proc 1985;17:264-271. [PubMed: 20354567]

19. Starzl, TE.; Putnam, CW. Experience in hepatic transplantation. Saunders; Philadelphia: 1969. p. 130-133.

20. Starzl TE, Iwatsuki S, Van Thiel DH, Gartner JG, Zitelli J, Malatack J, Schade RR, Shaw BW, Hakala TR, Rosenthal T, Porter KA. Evolution of liver transplantation. Hepatology 1982;2:614-636. [PubMed: 6749635]

21. Starzl TE, Iwatsuki S, Shaw BW Jr. A growth factor in fine vascular anastomoses. Surg Gynecol Obstet 1984;159:164-165. [PubMed: 6379938]

22. Starzl TE, Iwatsuki S, Shaw BW Jr, Gordon RD. Orthotopic liver transplantation in 1984. Transplant Proc 1985;17:250-258. [PubMed: 3881862]

23. Starzl TE, Miller C, Broznick B, Makowka L. An improved technique for multiple organ harvesting. Surg Gynecol Obstet 1987;165:343-348. [PubMed: 3310285]

24. Todo S, Nery J, Yanaga K, Podesta L, Gordon R, Starzl TE. Extended preservation of human liver grafts with U.W. solution. JAMA 1989;261:711-714. [PubMed: 2642982]

25. Todo S, Demetris AJ, Makowka L, Teperman L, Podesta L, Shaver T, Tzakis A, Starzl TE. Primary nonfunction of hepatic allografts with preexisting fatty infiltration. Transplantation 1989;47:903905. [PubMed: 2655230]

26. Tzakis AG, Gordon RD, Shaw BW Jr, Iwatsuki S, Starzl TE. Clinical presentation of hepatic artery thrombosis after liver transplantation in the cyclosporin era. Transplantation 1985;40:667-671. [PubMed: 3907040] 
27. Weinbren, K. Aging changes in the liver. In: Bourne, GH., editor. Structural aspects of aging. Hafner; New York: 1961. p. 35-42.

28. Wood, RP.; Shaw, BW, Jr. Multiple organ procurement. In: Cerilli, GJ., editor. Organ transplantation and replacement. Lippincott; Philadelphia: 1988. p. 322-326.

29. Yanaga K, Kanematsu T, Takenaka K, Matsumata T, Yoshida Y, Sugimachi K. Hepatic resection for hepatocellular carcinoma in elderly patients. Am J Surg 1988;155:238-241. [PubMed: 2829639] 


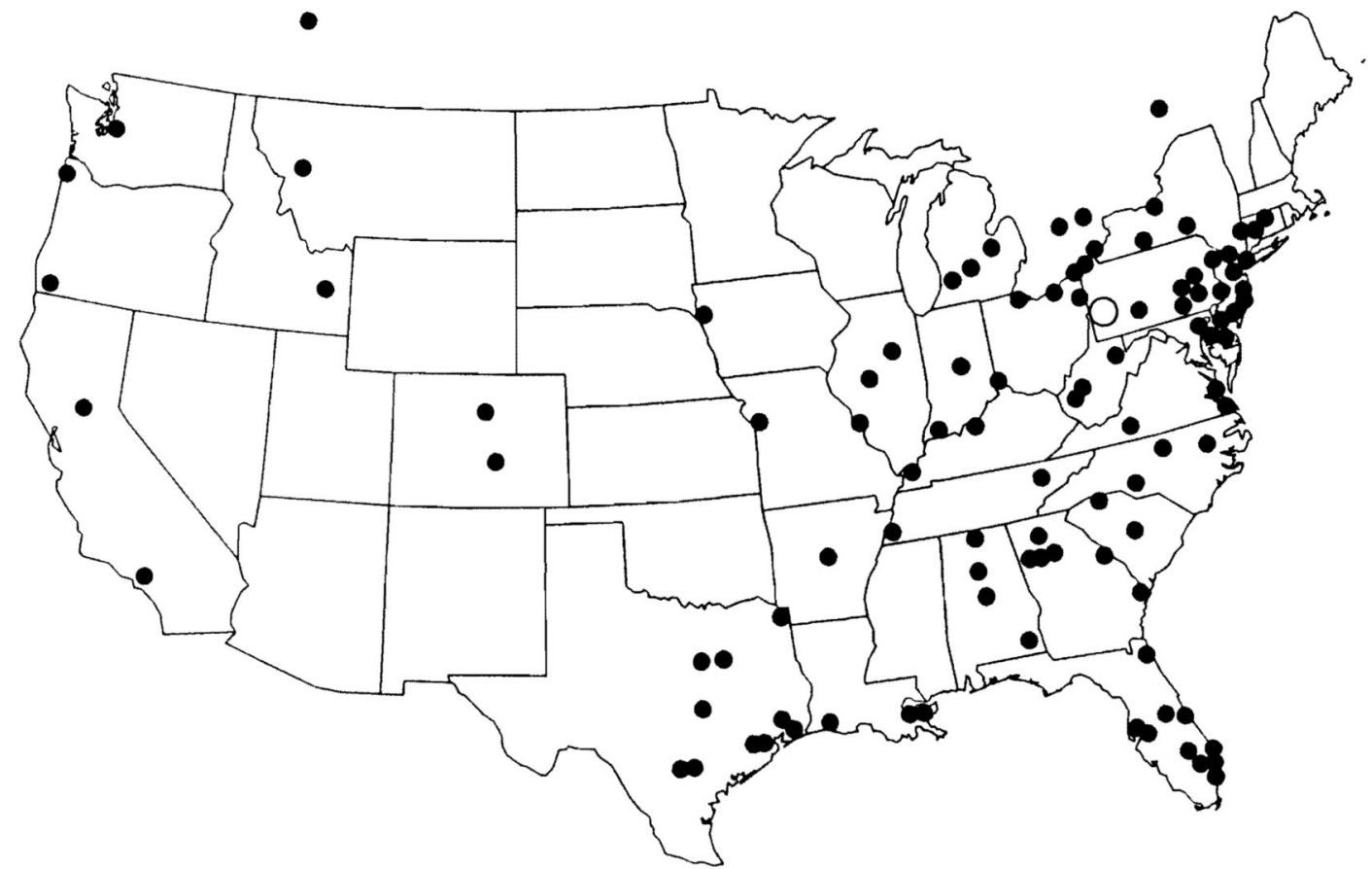

Fig. 1.

Location of the donors 


\section{Table 1}

Causes of brain death among 128 liver donors

\begin{tabular}{lr}
\hline Cause & $N$ \\
\hline Trauma & $89(69.5 \%)$ \\
Motor vehicle accident & 60 \\
Fall & 6 \\
Gunshot wound & 19 \\
Other & 4 \\
Cerebrovascular accident & $20(15.6 \%)$ \\
Subarachnoid hemorrhage & 19 \\
Cerebral infarct & 1 \\
Other & $19(14.8 \%)$ \\
Anoxic brain damage & 11 \\
Brain tumor & 2 \\
Cerebral embolism & 1 \\
Bacterial meningitis & 2 \\
Unknown & 3 \\
Total & $128(100 \%)$ \\
\hline
\end{tabular}

Transpl Int. Author manuscript; available in PMC 2010 October 6. 


\section{Table 2}

Criteria for the classification of early graft function.

\begin{tabular}{lllll}
\hline Variable & \multicolumn{4}{l}{ Early graft function } \\
& Good & Fair & Poor & GNFN $^{\boldsymbol{a}}$ \\
\hline SGOT (IU/l) & $<1500$ & $1500-3500$ & $>3500$ & - \\
SGPT (IU/1) & $<1000$ & $1000-2500$ & $>2500$ & - \\
FFP requirement & No & No & Yes & - \\
\hline
\end{tabular}

${ }^{a}$ Defined as the inability of the liver allograft to sustain the metabolic homeostasis of the recipient

GNFN, Graft nonfunction; FFP, fresh frozen plasma 


\section{Table 3}

Vascular reconstruction for hepatic arterial anomalies.

\begin{tabular}{|c|c|c|}
\hline Anomaly & $n$ & Method of reconstruction $(n)$ \\
\hline Aberrant RHA & $14(10.9 \%)$ & \\
\hline from SMA & 13 & $\begin{array}{l}\text { Donor SpA to aberrant RHA (10) } \\
\text { Aortic fold-over (1) } \\
\text { None }^{a}(2)\end{array}$ \\
\hline from aorta & 1 & Donor SpA to aberrant RHA (1) \\
\hline Aberrant LHA & $16(13.3 \%)$ & \\
\hline from CA & 14 & None (14) \\
\hline from aorta & 3 & $\begin{array}{l}\text { Donor SpA to PHA (1) } \\
\text { None (2) }\end{array}$ \\
\hline $\begin{array}{l}\text { Aberrant RHA } \\
\text { and LHA }\end{array}$ & $6^{b}(5 \%)$ & \\
\hline RHA from SMA & & Donor SpA to RHA (5) \\
\hline LHA from CA & & CA to distal SMA (1) \\
\hline Total & $37(28.9 \%)$ & \\
\hline
\end{tabular}

${ }^{a}$ Both were missing the PHA

${ }^{b}$ One was missing the PHA

RHA, Right hepatic artery; SMA, superior mesenteric artery; SpA, splenic artery; LHA, left hepatic artery; CA, celiac axis; PHA, proper hepatic artery 


\section{Table 4}

Early graft function after orthotopic liver transplantation.

\begin{tabular}{lccc}
\hline \multirow{2}{*}{$\begin{array}{l}\text { Early graft } \\
\text { function }\end{array}$} & \multicolumn{2}{c}{ Number of recipient problems } & Total \\
\cline { 2 - 3 } & No & Yes & \\
\hline Good & $74(67.9 \%)$ & $4(33.3 \%)$ & $78(64.5 \%)$ \\
Fair & $23(21.1 \%)$ & $2(16.7 \%)$ & $25(20.7 \%)$ \\
Poor & $6(8.3 \%)$ & $5(41.7 \%)$ & $14(11.6 \%)$ \\
GNFN & $3(3.5 \%)$ & $1(8.3 \%)$ & $4(3.3 \%)$ \\
Total & $109(100 \%)$ & $12(100 \%)$ & $121(100 \%)$ \\
\hline
\end{tabular}

${ }^{a}$ Consists of hepatic artery thrombosis in 7, portal vein thrombosis in 2, severe pancreatitis in 2, and prolonged warm ischemia in one patient GNFN, Graft nonfunction.

${ }^{*}<0.005\left(\chi^{2}=12.81\right)$ when good/fair and poor/nonfunction were compared between recipients with and without problems 
Table 5

Correlation between donor or graft variables and early graft function.

\begin{tabular}{|c|c|c|c|c|}
\hline \multirow[t]{2}{*}{ Variable } & \multicolumn{4}{|c|}{ Early graft function } \\
\hline & $\begin{array}{l}\text { Good } \\
(n=74)\end{array}$ & $\begin{array}{l}\text { Fair } \\
(n=23)\end{array}$ & $\begin{array}{l}\text { Poor } \\
(n=9)\end{array}$ & $\begin{array}{l}\text { Nonfunction } \\
(n=3)\end{array}$ \\
\hline Age (years) ${ }^{a b}$ & $19.9 \pm 10.9$ & $22.2 \pm 8.6$ & $25.8 \pm 12.8$ & $32.3 \pm 9.3$ \\
\hline Sex (M:F) & $46: 28$ & $16: 7$ & $7: 2$ & $1: 2$ \\
\hline \multicolumn{5}{|l|}{ Cause of death } \\
\hline $\begin{array}{l}\text { Motor vehicle } \\
\text { accident }(n=55)\end{array}$ & $35(63.6 \%)$ & $13(23.6 \%)$ & $6(10.9 \%)$ & $1(1.8 \%)$ \\
\hline $\begin{array}{l}\text { Subarachnoid } \\
\text { hemorrhage } \\
(n=15)\end{array}$ & $11(73.3 \%)$ & $1(6.7 \%)$ & $2(13.3 \%)$ & $1(6.7 \%)$ \\
\hline $\begin{array}{l}\text { Gunshot wound } \\
(n=15)\end{array}$ & $12(80 \%)$ & $2(13.3 \%)$ & $1(6.7 \%)$ & 0 \\
\hline Anoxia $(n=7)$ & $5(71.4 \%)$ & $2(28.6 \%)$ & 0 & 0 \\
\hline Other $(n=17)$ & $11(64.7 \%)$ & $4(23.5 \%)$ & $1(5.9 \%)$ & $1(5.9 \%)$ \\
\hline \multicolumn{5}{|l|}{ Lab data } \\
\hline SGOT (IU/l) ${ }^{a}$ & $78.7 \pm 58.1$ & $60.3 \pm 37.9$ & $101.2 \pm 68.9$ & $70 \pm 81.5$ \\
\hline SGPT (IU/l $)^{a}$ & $43.5 \pm 33.1$ & $61 \pm 55.1$ & $68.6 \pm 44$ & $36 \pm 20.9$ \\
\hline T.Bil $(\mathrm{mg} / \mathrm{dl})^{a}$ & $0.75 \pm 0.4$ & $0.81 \pm 0.39$ & $0.61 \pm 0.42$ & $1.1 \pm 0.79$ \\
\hline $\mathrm{PT}(\mathrm{s})^{a}$ & $15.6 \pm 1.7$ & $13.4 \pm 1.65$ & $13 \pm 1.1$ & $12.6 \pm 0.9$ \\
\hline ICU stay (days) ${ }^{a c}$ & $3.7 \pm 2.7$ & $5.7 \pm 2.7$ & $5.8 \pm 1.7$ & $3.3 \pm 1.5$ \\
\hline CPR & $13(19.4 \%)$ & $3(16.7 \%)$ & 0 & 0 \\
\hline $\begin{array}{l}\text { High dose } \\
\text { vasopressors }\end{array}$ & $28(37.8 \%)$ & $7(30.8 \%)$ & $2(22.2 \%)$ & 0 \\
\hline $\begin{array}{l}\text { Instability during } \\
\text { procurement }\end{array}$ & $16(21.6 \%)$ & $2(8.7 \%)$ & $2(22.2 \%)$ & $2(66.7 \%)$ \\
\hline $\begin{array}{l}\text { Abnormal graft } \\
\text { appearance } d\end{array}$ & $18(25.7 \%)$ & $5(21.7 \%)$ & $5(55.6 \%)$ & $1(33.3 \%)$ \\
\hline $\begin{array}{l}\text { Technique } \\
\text { (rapid :modified) }\end{array}$ & $30: 44$ & $6: 17$ & $1: 8$ & $0: 3$ \\
\hline $\mathrm{CIT}(\min )^{a}$ & $499 \pm 206$ & $624 \pm 349$ & $473 \pm 229$ & $357 \pm 95$ \\
\hline \multicolumn{5}{|l|}{$\mathrm{Mean} \pm \mathrm{SD}$} \\
\hline \multicolumn{5}{|c|}{${ }^{b} P<0.05$ when grafts with good/fair and poor/nonfunction are compared } \\
\hline \multicolumn{5}{|c|}{$\begin{array}{l}c_{P}<0.005 \text { when grafts with good and fair/poor function are compared } \\
d_{P<0.05\left(\mathrm{X}^{2}=4.29\right) \text { when grafts with good/fair and poor function are compared }}\end{array}$} \\
\hline
\end{tabular}


Table 6

Comparison of preservation fluids and cold ischemia time.

\begin{tabular}{llrl}
\hline Preservation fluid & \multicolumn{3}{l}{ Preservation time $(\mathbf{m i n})$} \\
\cline { 2 - 4 } & Minimum & Maximum & Mean \pm SD $^{*}$ \\
\hline Euro-Collins $(n=39)$ & 240 & 472 & $348 \pm 67$ \\
UW $(n=70)$ & 282 & 1320 & $561 \pm 304$ \\
\hline
\end{tabular}

UW, University of Wisconsin solution;

${ }^{*}<0.0001$ 
Table 7

Comparison of preservation fluids and early graft function.

\begin{tabular}{lllll}
\hline $\begin{array}{l}\text { Preservation } \\
\text { fluid }\end{array}$ & \multicolumn{4}{l}{ Early graft function } \\
\cline { 2 - 5 } & $\begin{array}{l}\text { Good } \\
(\boldsymbol{n}=\mathbf{7 4})\end{array}$ & $\begin{array}{l}\text { Fair } \\
(\boldsymbol{n}=\mathbf{2 3})\end{array}$ & $\begin{array}{l}\text { Poor } \\
(\boldsymbol{n}=\mathbf{9})\end{array}$ & $\begin{array}{l}\text { Nonfunction } \\
(\boldsymbol{n}=\mathbf{3})\end{array}$ \\
\hline Euro-Collins & & & & \\
$(n=39)$ & $25(64.1 \%)$ & $10(25.6 \%)$ & $3(7.7 \%)$ & $1(2.6 \%)$ \\
$\mathrm{UW}(n=70)$ & $49(70 \%)$ & $13(18.6 \%)$ & $6(8.6 \%)$ & $2(2.9 \%)$ \\
\hline
\end{tabular}

UW, University of Wisconsin solution 